\title{
Health insurance enrollment strategies during the Affordable Care Act (ACA): a scoping review on what worked and for whom
}

Angelo Ercia ${ }^{1 *} \mathbb{D}, \mathrm{Nga} \mathrm{Le}^{2}$ and Runguo $\mathrm{Wu}^{3}$

\begin{abstract}
Background: The Affordable Care Act (ACA) provided an opportunity for millions of people in the U.S. to get coverage from the publicly funded Medicaid program or private insurance from the newly established marketplace. However, enrolling millions of people for health insurance was an enormous task. The aim of this review was to examine the strategies used to enroll people for health insurance and their effectiveness after implementing the ACA's coverage expansion.
\end{abstract}

Methods: The PRISMA Extension for Scoping Review (PRISMA-SCR) guided this review. Included studies were empirical studies that met the inclusion criteria and published between 2010 and 2020. Studies were searched mainly from two scholarly databases, CINAHL Plus and Medline (PubMed) using keyword searches. Hand searches from the references of selected journals were also performed. Content analysis was conducted by two authors in which codes were inductively developed to identify themes.

Results: There were 2213 potential studies identified from the search, but 10 met the inclusion criteria. The research design of the studies varied. Two studies were randomized trials, one quasi-experimental trial, three mixedmethods, two qualitative and two quantitative. All studies focused on strategies used to inform and help people enroll for either Medicaid or private insurance from the marketplace. This review identified three key strategies used to help enroll people for coverage: 1 ) individual assistance; 2) community outreach; and 3) health education and promotion (HE\&P).

Conclusion: Community-based organizations were likely to use a combination of the three strategies simultaneously to reach uninsured individuals and directly help them enroll for health insurance. Other organizations that aimed to reach a wider segment of the population used single strategies, such as community outreach or HE\&P.

Keywords: The affordable care act, Medicaid, Private insurance, Insurance enrollment

\footnotetext{
* Correspondence: aenercia06@gmail.com

${ }^{1}$ Centre for Health Informatics, Division of Informatics, Imaging and Data Sciences, University of Manchester, Manchester, UK

Full list of author information is available at the end of the article
}

(c) The Author(s). 2021 Open Access This article is licensed under a Creative Commons Attribution 4.0 International License, which permits use, sharing, adaptation, distribution and reproduction in any medium or format, as long as you give appropriate credit to the original author(s) and the source, provide a link to the Creative Commons licence, and indicate if changes were made. The images or other third party material in this article are included in the article's Creative Commons licence, unless indicated otherwise in a credit line to the material. If material is not included in the article's Creative Commons licence and your intended use is not permitted by statutory regulation or exceeds the permitted use, you will need to obtain permission directly from the copyright holder. To view a copy of this licence, visit http://creativecommons.org/licenses/by/4.0/. The Creative Commons Public Domain Dedication waiver (http://creativecommons.org/publicdomain/zero/1.0/) applies to the data made available in this article, unless otherwise stated in a credit line to the data. 


\section{Background}

Implementing the Affordable Care Act's (ACA) coverage expansion in 2014 provided the opportunity for millions of uninsured people in the United States (U.S.) to gain coverage. The ACA was able to accomplish this by simultaneously expanding the publicly funded insurance program, Medicaid, and private insurance through the establishment of the marketplace. The first 5 years of the ACA's implementation enabled about 10.8 million people to gain coverage from Medicaid and 11.7 million to gain coverage from private insurance [1].

Despite the millions of people gaining insurance from the ACA, the Congressional Budget Office estimated 23 to 26 million people would remain uninsured [2]. Several factors contributed to the ACA's inability to eliminate uninsurance. One factor was the Supreme Court's ruling that made Medicaid expansion an option for state governments. Thirty-nine states including the District of Columbia (D.C.) have expanded Medicaid while 12 states have not expanded [3], thus putting many low-income nonelderly adults at risk of remaining uninsured [4]. Purchasing private insurance from the newly established marketplace was an option for nonelderly adults unable to get Medicaid, but some found it unaffordable even with the possibility of receiving federal subsidies [5].

Another factor that may have also contributed to people remaining uninsured was navigating the enrollment process for coverage [6, 7]. Many people had limited understanding of health insurance, the enrollment process [8-10] and misunderstanding of the ACA [11]. The federal government, in collaboration with state and local governments, enacted multiple strategies to help people enroll for coverage. For example, a "no wrong door" enrollment system enabled people to enroll for Medicaid or private insurance on a centralized website [12]. The federal government also established the Consumer Assistance Program to conduct outreach and help people experiencing any problems with the enrollment process or post enrollment issues such as appealing to any denied claims [13]. Some state managed health insurance marketplaces established an assistance program for people to receive guidance on selecting, understanding, and enrolling to an insurance plan [13]. There are many other strategies used by local organizations. However, there is still limited understanding of the strategies used and their effectiveness in helping people enroll for coverage [14]. Therefore, this scoping review aims to identify and synthesize the strategies used during the ACA to help enroll nonelderly adults for Medicaid or private insurance and their effectiveness.

\section{Methods}

\section{Search strategies and selection criteria}

This review explored the strategies used and their effectiveness during the ACA to enroll uninsured people for coverage. The PRISMA Extension for Scoping Review (PRISMA-ScR) guide [15] directed the search for peerreviewed literature. We conducted our literature search on two scholarly databases, CINAHL Plus and Medline (PubMed) from March to May 2020. The following search terms were used in both databases: "The ACA" [OR] "The Affordable Care Act" [OR] "The Patient Protection and Affordable Care Act" [AND] "enrollment" [OR] "take up" [AND] "health insurance". We also conducted hand searches from the references of selected journals.

The following are the inclusion criteria for the studies selected for this review: 1) empirical studies that investigated the enrollment strategies used to enroll people for health insurance under the ACA, 2) described research design and methods, 3) focused on nonelderly adults (ages 18-64), 4) studies occurred between January 2010-December 2020, 5) and studies written in English. The following are the exclusion criteria that excluded studies from this review: 1) studies not specifically investigating enrollment strategies used during the ACA's coverage expansion, 2) studies that primarily focused on enrolling children or elderly adults for coverage, 3) systematic reviews, editorials/ commentaries, grey literature or reports.

\section{Analysis}

$\mathrm{AE}$ and $\mathrm{NL}$ independently screened the search results by reviewing the title and abstract of each study and assessed whether they met the inclusion criteria. They compared their selections and discussed any discrepancies to meet consensus whether to include or remove them. This process occurred in several iterations to ensure the articles met the aim of the review. The authors then conducted content analysis on the selected articles. The initial process included reading through the literature passages and identifying the enrollment strategies to inductively develop a coding framework. The coding framework included various elements of the enrollment strategies such as their strength, weaknesses, barriers, and limitations. This enabled the team to identify themes.

\section{Results}

The search produced a total of 2213 articles. Ten articles were included in the review as they met the selection criteria (see Fig. 1). The selected articles varied in its research design and included two randomized trials, one quasi-experimental trial, three mixed-methods, two qualitative, and two quantitative 


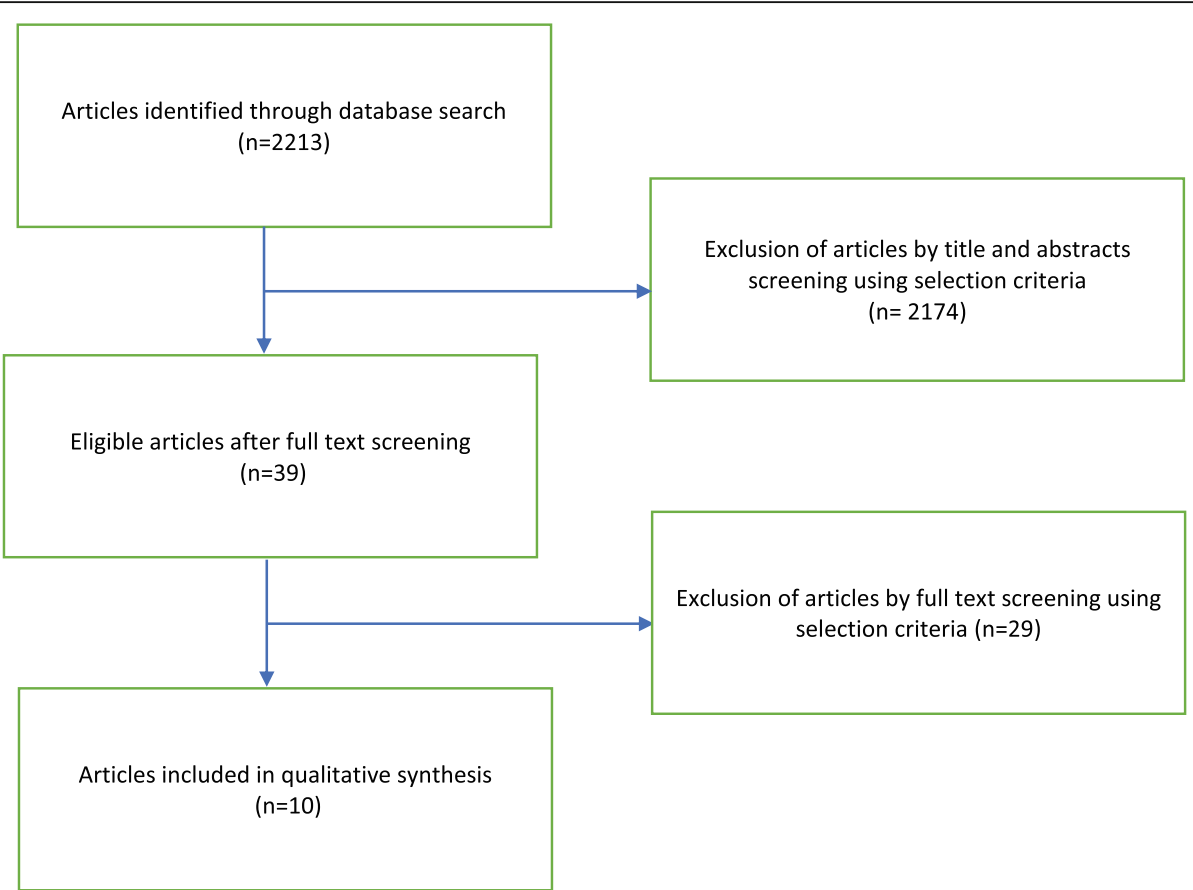

Fig. 1 Flow chart of selected articles

studies. Most of the studies investigated strategies used to encourage uninsured individuals to get coverage from the Medicaid program or private insurance from the marketplace. Two studies only investigated strategies to help enroll uninsured individuals for Medicaid. Three studies focused on strategies to enroll people for marketplace private insurance. The supplementary document (Supplementary file 1) summarizes key characteristics of the selected studies, such as study aim, design, target population, insurance coverage, and location.

\section{Enrollment strategies}

We identified three key strategies used to help enroll people for health insurance. These strategies were 1) individual assistance, 2) community outreach, and 3) health education and promotion (HE\&P). Specific strategies were not only used to help people enroll for either Medicaid or private insurance. However, some organizations (e.g., Federally Qualified Health Centers and community-based organizations) implemented comprehensive approaches that incorporated aspects of the three strategies. Table 1 provides a summary of the enrollment strategies.

\section{Individual assistance}

Most of the studies identified [16-22] individual assistance as a key strategy used by healthcare providers and community-based organizations to help people enroll for health insurance. The terminology used to describe individual assistance varied. It included terms such as certified application counselors, navigators, community health workers, assisters, enrollment workers, and promotores. While organizations used different terminology, they had similar roles and responsibilities. Assisters aimed to provide in-person education to individuals about their coverage options; screen for insurance eligibility, either for Medicaid or marketplace private insurance; provide assistance and support to complete the application process. Assisters also provided help that went beyond enrolling for coverage such as submitting the correct supporting documents, renewing coverage, and helping individuals change their primary care provider. Some assisters working for Federally Qualified Health Centers (FQHCs) and communitybased clinics (non-FQHC clinics) also engaged in community outreach. These outreach events included health education workshops and other face-to-face interactive events that enabled them to disseminate information about health insurance and enrolling for coverage [17].

Some FQHCs and community-based organizations had assistance programs prior to the implementation of the ACA. These organizations expanded their capacity to help more people once the ACA coverage expansion took effect by hiring more assisters [17-22]. Other organizations such as The Weill Cornell Community Clinic (WCCC) utilized their licensed social worker to screen patients for coverage eligibility and collaborated with another community organization to help their patients complete the enrollment process [18]. 
Table 1 Description of enrollment strategies from selected studies between January 2010 and December 2020

\begin{tabular}{ll}
\hline Author & Location \\
\hline $\begin{array}{l}\text { Individual assistance } \\
\text { Call et al. [16] }\end{array}$ & Minnesota (statewide) \\
Getrich et al. & New Mexico (urban \& rural areas) \\
[17] & \\
McGeehan et & New York (New York City) \\
al. [18] & \\
Orzol \& Hula & Arizona, Florida, Georgia, Illinois, Michigan, New Jersey, \\
[19] & North Carolina, Ohio, Pennsylvania, Tennessee, Texas \\
Politi et al. & Missouri (St. Louis region) \\
[20] & \\
& \\
Raymond- & California (urban \& rural areas) \\
Flesch et al. & \\
[21] & \\
Viramontes et & California (southern) \\
al. [22] & \\
Community outreach
\end{tabular}

Call et al. [16] Minnesota (statewide)

Getrich et al. New Mexico (urban \& rural areas)

[17]

Orzol \& Hula Arizona, Florida, Georgia, Illinois, Michigan, New Jersey, [19] North Carolina, Ohio, Pennsylvania, Tennessee, Texas

Viramontes et California (southern)

al. [22]

\section{Health Education \& Promotion (HE\&P)}

Call et al. [16] Minnesota (statewide)

Getrich et al. New Mexico (urban \& rural areas)

[17]

Marzilli- Colorado (statewide)

Ericson et al.

[23]

Karaca-

Mandic et al.

[24]

Orzol \& Hula Arizona, Florida, Georgia, Illinois, Michigan, New Jersey, [19] North Carolina, Ohio, Pennsylvania, Tennessee, Texas

Viramontes et California (southern)

al. [22]

Wright et al. Oregon (statewide)

[25]

\section{Description}

- Located in various locations.

- Provided education on coverage options.

- Provided support throughout the enrollment process.

- FQHCs and community health centers, (academic health centers, faith-based clinics) had navigators to provide in person assistance.

- Social workers determined individuals' insurance eligibility. - Referred individuals to a facilitated enroller from a local non-profit organization for additional support.

- Collected individual contact to follow-up and provide information on health insurance coverage, enrollment, and key deadlines. - Collaborated with local organizations to extend reach.

- Online decision aid called "Show Me My Health Plan" (SMHP). - SMHP aimed to 1) simplify written information and graphics 2) activities to assess understanding of health insurance information 3) Financial calculator for plans 4) assess appropriateness of selected plan based on need.

- Provided in-person assistance for people enrolling for coverage (Medicaid or private insurance) and other entitlement programs.

- Offered in-person enrollment support.

- Organized outreach events in community centers, places of worship, townhalls.

- Collaborated with small business groups and healthcare providers.

- Outreach activities that aimed to disseminate information on health insurance.

- Outreach events occurred in different forms (e.g., workshops, health sessions) in communal settings.

- Field outreach to communities in 11 states that did not expand the Medicaid program.

- Disseminated information about private insurance.

- Organized workshops and community events (e.g., health fairs, 5K races, school site visits) to disseminate information and resources in communities.

- Developed educational and promotional materials.

- Organized print and social media campaigns.

- Disseminate information on health insurance in multi-language and various advertisement campaigns.

- Enhanced nudging system (included paper-based letters and emails) in the state marketplace website to encourage people to shop and change their plan.

- Televised advertisement on health insurance directed to uninsured adults under age 65 during open enrolment.

- Advertisement came from various sources: insurance advertisements, political advertisements, and local news coverage.

- Online media campaigns to inform people about the ACA and resources available on their website to enroll for coverage.

- Multi-channel advertisement campaign (e.g., billboards, digital marketing, and radio) to disseminate information about the ACA and enrolling for coverage.

- Enhanced materials and nudges that aimed to improve Medicaid enrollment.

- Developed simplified information on health insurance, enrollment, and deadlines. 
Table 1 Description of enrollment strategies from selected studies between January 2010 and December 2020 (Continued)

\begin{tabular}{ll}
\hline Author Location & Description \\
\hline & $\begin{array}{l}\text { - Provided generic and personalized messaging (letter, emails, } \\
\text { telephone calls) during key deadlines. }\end{array}$
\end{tabular}

While FQHCs and community-based organizations used in-person individual assisters to help people enroll for coverage, automated web-based assisters emerged in some state marketplace website. The "Show Me My Health Plan" (SMHP) was an online decision aid system integrated in Missouri's state-run marketplace website [20]. It helped individuals purchase private insurance in the marketplace by simplifying information and graphics, developed interactive activities to assess understanding of health insurance, and provided individualized report to ease the selection of a plan that met their financial and healthcare needs.

\section{Community outreach}

Four studies $[16,17,19,22]$ examined the role of community outreach as a strategy to inform and link people to enrollment resources. FQHCs and community-based organizations conducted outreach by organizing community events (e.g., $5 \mathrm{~K}$ runs, health fairs), workshops, and community meetings [22]. These events took place in various community locations that included schools, community centers, places of worship, and town halls $[16,17,22]$. Studies did not specifically describe the activities that took place in these outreach events. However, the primary aim was to widely distribute information about the ACA, health insurance, and enrollment resources while building trust and relationship with the communities they served. It also enabled organizations to connect people needing additional help to individual assisters when necessary. For example, the Enroll America program established in multiple nonexpanded Medicaid states used community outreach events to connect with individuals to provide information and support to help them with the enrollment process [19].

\section{Health Education \& Promotion (HE\&P)}

Individual assistance and community outreach would not be possible without effective health education and promotion initiatives. Seven studies [16, 17, 19, 22-25] highlighted the importance of developing enhanced educational and promotional materials about the ACA policy, health insurance, and the enrollment process. Four studies $[16,17,19,22]$ primarily highlighted the role of developing health education and promotion messages to carry out communication campaigns through different media outlets (e.g., digital, online, print, radio, social media) to increase awareness of the ACA and the opportunity to enroll for coverage. Karaca-Mandic et al. [24] investigated the impact of TV advertisement from different sources (private insurance companies, state, news, political advertisement) and its impact on enrollment.

Two studies $[23,25]$ investigated a different type of HE\&P strategy used in two states. The nudging system aimed to distribute direct enhanced educational and promotional materials through paper-based and/or online platform to individuals. The Colorado state marketplace used the nudging system to encourage individuals to shop and potentially change their plans as necessary. The state of Oregon used a similar system to encourage eligible individuals to enroll for the Medicaid program.

Effectiveness of enrollment strategies The three strategies used to enroll people for coverage had a different level of effectiveness. Table 2 summarizes the advantages and disadvantages of each strategy.

\section{Individual assistance}

Individual assistance helped uninsured individuals with limited or no knowledge of health insurance and the enrollment process for Medicaid or marketplace private insurance [16, 17]. Uninsured individuals that gained coverage were seven more times likely to receive help from an assister than individuals that remained without coverage [16]. By contrast, AltaMed, the largest community health center in Southern California, found that individual assisters helped over 19,000 people to enroll for coverage during the first year of open enrollment and over 15,000 people during the second year [22]. This strategy was effective because individual assisters helped people select an insurance plan and navigate the enrollment process. Assisters' ability to build trust with individuals was also found to be key factor to the strategy's success $[16,17,22]$. A limitation for assisters was the amount of time they could dedicate to individuals. For example, social workers in WCCC spent 25 min per patient to discuss their options for coverage [18] while navigators in FQHCs spent an hour per patient [17]. The ability of assisters to help people enroll for coverage also heavily relied on their knowledge of healthcare plans and skill to navigate the enrollment system. Enrollment training varied among organizations and was impacted by constant policy changes (e.g., changes in the ACA, immigration and tax rules) in states $[17,21,22]$. Technical problems with the enrollment system was also a common problem that delayed the process $[17,21,22]$. The online SMHP program of Missouri's marketplace website was also effective in helping to increase users' 
Table 2 Advantages and disadvantages of enrollment strategies from selected studies between January 2010 and December 2020

\begin{tabular}{ll}
\hline Enrollment strategy & Advantages \\
\hline Individual assistance & \\
In-person assistance & - Helped individuals understand their options for coverage \\
& and get support to complete enrollment process [16-18, 22] \\
& - Offered support and resources to individuals new to health \\
& insurance, immigrants and undocumented migrants living in \\
& rural and semi-urban areas [17]. \\
& - Established trust and respect from individuals [17]. \\
& - Provide structured approach to helping individuals enroll \\
& for coverage and maintain records on the number enrollees \\
& [17, 18]. \\
& - Identified knowledge gap on enrollment and the ACA \\
& policy, barriers to enrollment, and technical issues [21]. \\
& - Improve individual knowledge on health insurance, plan \\
Selection[20]. & - increase individual confidence in selecting a marketplace \\
Online decision aid & plan
\end{tabular}

\section{Community outreach}

Community events (e.g., - Encouraged populations to learn about health insurance health fairs, 5 K-runs, school visits)

coverage $[16,17]$.

- Informed populations about resources to help with enrollment $[16,17]$.

- Helped increase private insurance enrollment in nonexpanded state [19].

- Informed populations that were less likely to be informed about their coverage options under the ACA (e.g., young adults, immigrants) [17, 19, 22].

Educational events (e.g., - Provided health insurance information and enrollment workshops, health resources during health-related workshops [17] sessions)

\section{Health Education \& Promotion (HE\&P)}

Educational/ promotional materials

Social media/ online campaigns

Advertisement campaigns (e.g., print, radio, TV ads)

Nudging system (paper-based or online)
- Simplified information on health insurance and coverage eligibility for people had a wide reach [16].

- Informed large segment of the population about the ACA [17].

- Informed people how to access educational materials and resources to enroll for coverage [16].

- Reach larger segment of the population with minimal resources $[17,24]$

- The public positively responded to health insurance information from TV advertisement. High volume of advertisements during open enrollment was associated with increase enrollment for coverage [24].

- Encouraged people to visit the marketplace website and review the information [23].

- Low-cost tools (letters, emails) were just as effective than higher intensity tools to encourage individuals to enroll for coverage [25].

\section{Disadvantages}

- Time consuming [16-18].

- Unable to provide support to everyone in need due to limited capacity [16-18].

- Unable to enroll individuals when technical and operations problems with enrollment system occurs [16, 17, 21, 22].

- Updated training to assisters can be challenging especially with ongoing changes in the ACA and other enrollment policies $[17,21,22]$.

- Cannot determine specific aspects of an online decision aid (e.g., educational materials, cost calculator, values component) that helped individuals decide a Marketplace plan [20].

- Only used by people living within a 90-mile radius of St Louis City [20].

- Time consuming $[16,17]$.

- Dependent on capacity and ability to organize events [17].

- Time-consuming and may require multiple sessions for people to absorb the information [17].

- Some people continue to struggle with the enrollment process [16]

- Segment of the populations were not exposed to the educational materials or campaigns $[16,17]$.

- Require multiple exposure for people to absorb the information [17].

- The source of the information mattered. People can be negatively affected by certain TV ads. Negative political advertisement on the ACA was associated with declining Medicaid enrollment [24].

- The enhanced nudging system did not cause many people to switch plan [23].

- Segment of the population (e.g., elderly) may not have access to technology and/or have limited skills to utilize it [23]. health insurance literacy and their self-efficacy to decide an appropriate coverage plan for their need [20]. As a result, users were less likely to seek help from in-person assisters. A limitation with SMHP, however, was the inability to identify specific functions that helped people decide an insurance plan in the marketplace and whether it eased the enrolment process.

\section{Community outreach}

Community outreach took on many forms and was effective in disseminating information and resources to the public. This strategy was particularly effective in engaging with specific segments of the populations that were less informed about the ACA and resources such as first-time enrollees for health insurance, immigrants, and the undocumented populations. The 
MNsure program in Minnesota found that $76 \%$ of uninsured individuals that were exposed to their outreach activities sought more information about health insurance [16]. The Enroll America program found that their outreach activities contributed to the increase in private insurance enrollment in states that implemented a federally facilitated marketplace [19]. Rural FQHCs and semi-urban community health centers also discovered that conducting outreach activities enabled them to connect with immigrant populations that experienced significant challenges enrolling for health insurance [17]. A major limitation of this approach was the time commitment and resources needed for organizations to organize events $[16,17]$.

\section{Health Education \& Promotion (HE\&P)}

Similar to community outreach, health education and promotion strategies aimed to disseminate information about the ACA and the opportunity to enroll for coverage. However, this strategy could reach a larger population with minimal resources through multimedia campaigns. Karaca-Mandic et al. [24] found that the source of the information mattered as state sponsored television advertisement was more effective in encouraging people to enroll for coverage during the open enrollment period compared to advertisements from private insurance companies, news, and political advertisements on the ACA. They found that higher volume of political advertisement on the ACA may have discouraged people to enroll for Medicaid. Advertisement from private sponsors (e.g., private insurance plans) were also not found to encourage people to enroll for insurance.

The nudging system was effective in encouraging people with marketplace insurance to access information on state websites to consider changing their insurance plan [23]. Medicaid eligible individuals benefitted from receiving information and reminders to enroll for the program [25]. An advantage with this strategy is its relatively low-cost and minimal resources to develop. For example, the nudging system that used low-cost strategies such as sending generalized letters, postcards, emails, and automated telephone calls were just as effective as personalized and higher cost strategies that included in-person outreach and individualized assistance in encouraging people to enroll for either coverage type $[23,25]$. A disadvantage of an online nudging system is not everyone has access to technological devices to get the information and access the resources. It may also favor certain population as younger people were more likely to respond to online nudges compared to older people, as they may have better access to computer and emails [23].

\section{Discussion}

Implementing the ACA's coverage expansion provided the opportunity for many uninsured people to gain health insurance. However, enrolling millions of people for coverage was a monumental task. This review aimed to determine the strategies used during the ACA's coverage expansion and their effectiveness in enrolling people for health insurance. We found the three key strategies used to help enroll people for coverage were: 1) individual assistance, 2) community outreach, and 3) health education and promotion (HE\&P).

Individual assisters aimed to provide information and direct support to uninsured individuals that had limited or no knowledge of getting health insurance under the ACA. While they could only reach a finite number of people, their role was essential because they were directly helping people to enroll for coverage. Our findings are supported by Artiga et al. [12] that found individual assisters had an essential role in helping people enroll for Medicaid in four states (Colorado, Connecticut, Kentucky, and Washington) that expanded the program. Artiga et al. [12] and the findings of this review also suggest that assisters are well suited to help people enroll for coverage because they could develop strong ties with the community and act as a broker during the enrollment process. In this role, they could identify problems with the enrollment process and quickly find solutions. While assisters were effective in helping enroll people for coverage, this strategy required extensive resources. Organizations needed to hire more staff to be assisters, provide ongoing enrollment training, and updated information to reflect constant changes in the ACA.

A plausible alternative to in-person individualized assistance is a web-based system. The online decision tool in Missouri's marketplace website was found to help increase people's literacy on private insurance and their confidence in choosing a plan. Insurance plan selection could be stressful, as it requires people to select an affordable plan that meets their healthcare service needs within the year [26]. Therefore, the decision tool may be useful to people that need help with selecting a plan but could complete the enrollment process themselves. A study conducted by Cosineau et al. [14] also found the usefulness of a technology-based assister to improve children's enrollment to California's Children's Health Insurance Program (CHIP) as it increased the enrollment by 10 to $11 \%$.

We found the two other strategies to be similar in their aims, but focused on reaching wider segments of the population to disseminate information and resources. Unlike individual assisters, the two strategies primarily aimed to encourage people to get health insurance rather than providing direct enrollment assistance. Community outreach was a strategy used to 
disseminate information about the ACA and resources on enrollment to the public. The strength of this approach was its focus on reaching specific populations by organizing interactive events that took place in community settings. Other studies have found this approach to be particularly important in reaching underserved populations [12, 27]. Uninsured lowincome and underserved individuals may not be engaged with any healthcare providers; therefore, outreach events must occur in locations where they conduct daily activities and socialize [27]. A limitation with this strategy, however, is the scale of its reach. Smaller events such as workshops could reach a handful of people with minimal resources. Larger events might reach hundreds of people with $5 \mathrm{~K}$ runs or community events in town halls, but require more resources and collaboration with multiple organizations.

The HE\&P strategy may be an alternative to community outreach when the aim is to reach a wider and diverse segment of the populations with minimal resources. Disseminating information is also possible through multiple communication platforms. While disseminating HE\&P information was found to be an effective way to encourage people to enroll for coverage, this review also found that the source of the information mattered. Information from certain sources, such as the state government, was more accepted by the public than from the federal government and private insurance. Information with a political agenda was less attractive to the public. It suggests that information from certain sources such as individual assisters or the state government may be more accepted by the public as they have built trust with the community and the public. They may also be seen as a trusted source of information as they aim to provide support to people enrolling for coverage. Artiga et al. [12] also found this in their study as stakeholders from Kentucky and various regions in Colorado, Connecticut and Washington believed statebranded HE\&P were important particularly when reaching individuals that were politically unsupportive with the ACA or had limited trust with federal government programs.

\section{Implication and limitation of the study}

The findings of this review suggest that there were three key strategies used to help enroll the public for health insurance under the ACA. Each strategy had its advantages and disadvantages, but combining all of them provided a comprehensive strategy that could reach individuals, specific groups, and the wider population. Because of the complexity of the enrollment process in the U.S. and the limited window period to enroll for health insurance coverage every year, implementing a combination of enrollment strategies might be more effective than a single strategy, especially for regions with diverse population with different needs. The findings of this review suggest that certain strategies are more effective for a specific segment of the population. For example, uninsured people that never had or have limited knowledge of health insurance and the enrollment process may benefit from receiving in-person help from an individual assister. In-person assistants were necessary for some individuals as they needed additional support to understand the benefit, cost, and use of health insurance and navigating the enrollment process. People that are familiar with health insurance and the enrollment process may need less support but benefit from an online assister system that provides simplified information and reminders of key dates to enroll for coverage. Community outreach strategies may be best used to disseminate information to specific segments of the population. By contrast, HE\&P strategies could better reach a wider and diverse population with minimal resources. Therefore, organizations that aim to implement strategies to help people enroll for coverage must consider their target population, capacity and resources.

This review aimed to assess the strategies used to enroll people for health insurance under the ACA by assessing peer-reviewed studies. A limitation of this review is the few studies that specifically investigated the strategies used during the ACA to help enroll people for health insurance coverage. More studies looked at the impact of expanding coverage rather than understanding the process of informing people about the opportunities on getting health insurance and enrolling them. A second limitation is the study design of the studies included in this review. Most studies were quasi-experimental case studies. This provided insight on the type of activities organizations implemented and their potential impact to enrollment. However, it was not possible to correlate the implemented strategies to the proportion of people they enrolled for coverage. There needs to be a more rigorous evaluation of specific strategies' effectiveness. Last, a limitation of this scoping review aimed to summarize the strategies used to enroll people for coverage rather than critically appraised and evaluate. As a result, a risk of bias must be considered with the evidence presented [28]. The implications presented in this review merely offer suggestions for considerations when implementing enrollment strategies.

\section{Conclusion}

This review found that three strategies were primarily used to assist uninsured individuals to enroll for coverage under the ACA: 1) individualized assistance, 2) community outreach, and 3 ) health education and promotion (HE\&P). Selected strategies were not exclusive to helping 
people enroll for specific coverage type. The findings suggest that the three strategies worked well on informing people about the ACA and the opportunity to gain coverage from Medicaid or private insurance. However, certain strategies may be more effective in providing support with the enrollment process to specific populations.

\section{Abbreviations}

ACA: Affordable Care Act; FQHC: Federally qualified health center: HE\&P: Health education and promotion; WCCC: Weill cornell community clinic; SMHP: Show me my health plan; U.S.: United States

\section{Supplementary Information}

The online version contains supplementary material available at https://doi. org/10.1186/s13690-021-00645-w.

Additional file 1:. Characteristics of selected studies.

\section{Acknowledgements}

Not applicable.

\section{Authors' contributions}

AE conceptualized and designed the study. AE and NL conducted the literature search, data analysis and interpretation. AE drafted the original manuscript and was reviewed by both $\mathrm{NL}$ and RW. AE, NL, and RW reviewed and edited several iterations of the manuscript. AE and RW supervised the study. All authors approved the final version.

\section{Funding}

The authors did not receive support from and organization for the submitted work. No funding was received to assist with the preparation of this manuscript.

\section{Availability of data and materials}

The data used for this study is available from the detailed reference list. No additional data was used for this study.

\section{Declarations}

\section{Ethics approval and consent to participate}

Ethnical approval not applicable as this was a review of published studies.

\section{Consent for publication}

Not applicable.

\section{Competing interests}

The authors declare that they have no conflicts of interest or competing interests.

\section{Author details}

${ }^{1}$ Centre for Health Informatics, Division of Informatics, Imaging and Data Sciences, University of Manchester, Manchester, UK. 'Department of Health \& Human Services, County of Marin, Marin, California, USA. ${ }^{3}$ Institute of Population Health Sciences, Queen Mary University of London, London, UK.

Received: 5 January 2021 Accepted: 21 June 2021

Published online: 12 July 2021

\section{References}

1. Blumenthal D, Abrams M, Nuzum R. The affordable care act at 5 years. $N$ Engl J Med. 2015;375:2451-8

2. Clemans-Cope L, Kenney GM, Buettgens M, Carroll C, Blavin F. The affordable care Act's coverage expansions will reduce differences in Uninsurance rates by race and ethnicity. Health Aff. 2012;31(5):920-30. https://doi.org/10.1377/hlthaff.2011.1086.

3. Kaiser Family Foundation. Status of State Action on the Medicaid Expansion Decision [Internet]. KFF.org. 2020 [cited 2020 Nov 16]. Available from: https://www.kff.org/health-reform/state-indicator/state-activity-around-expa nding-medicaid-under-the-affordable-care-act/

4. Collins SR, Rasmussen PW, Doty MM, Beutel S. The rise in health care coverage and affordability since health reform took effect. Washington, DC: Commonwealth Fund; 2015.

5. Patel MR, Jensen A, Ramirez E, Tariq M, Lang I, Kowalski-Dobson T, et al. Health insurance challenges in the post-affordable care act (ACA) era: a qualitative study of the perspective of low-income people of color in metropolitan Detroit. J Racial Ethnic Health Disparities. 2018;5(1):78-85. https://doi.org/10.1007/s40615-017-0344-2.

6. Sommers BD, Epstein AM. Medicaid expansion--the soft underbelly of health care reform? N Engl J Med. 2010;363(22):2085-7. https://doi.org/10.1 056/NEJMp1010866.

7. McMorrow S, Kenney GM, Coyer C. Addressing coverage challenges for children under the Affordable Care Act: Timely analysis of immediate health policy issues. USA: Robert Wood Johnson and Urban Institute; 2011. p. 1-10.

8. Jordan JE, Buchbinder R, Osborne RH. Conceptualising health literacy from the patient perspective. Patient Educ Couns. 2010;79(1):36-42. https://doi. org/10.1016/j.pec.2009.10.001.

9. Long SK, Kenney GM, Zuckerman S, Goin DE, Wissoker D, Blavin F, et al. The health reform monitoring survey: addressing data gaps to provide timely insights into the affordable care act. Health Affairs. 2014;33(1):161-7. https:// doi.org/10.1377/hlthaff.2013.0934.

10. Politi MC, Kaphingst KA, Kreuter M, Shacham E, Lovell MC, McBride T. Knowledge of health insurance terminology and details among the uninsured. Med Care Res Rev. 2014;71:85-98.

11. Barcellos SH, Wuppermann AC, Carman KG, Bauhoff S, McFadden DL, Kapteyn A, et al. Preparedness of Americans for the affordable care act. Proc Natl Acad Sci U S A. 2014;111(15):5497-502. https://doi.org/10.1073/pna S. 1320488111

12. Artiga S, Stephens J, Rudowitz R, Perry M. What worked and What's next? Strategies in four states leading ACA enrollment efforts - current and future priorities [internet]. Kaiser family oundation and PerryUndem research and communication; 2014 Available from: https://www.kff.org/report-section/ what-worked-and-whats-next-strategies-in-four-states-leading-acaenrollment-efforts-current-and-future-priorities/

13. Pollitz K, Tolbert J, Ma R. Survey of Health Insurance Marketplace Assister Programs. Kaiser Family Foundation; 2014 Jul p. 38. Report No.: 8611.

14. Cousineau MR, Stevens GD, Farias A. Measuring the impact of outreach and enrollment strategies for public health Insurance in California: measuring the impact of outreach and enrollment strategies. Health Serv Res 2011;46:319-335, 1p2, DOl: https://doi.org/10.1111/j.1475-6773.2 010.01202.x

15. Tricco AC, Lillie E, Zarin W, O'Brien KK, Colquhoun H, Levac D, et al. PeRISMA Extension for Scoping Reviews (PRISMA-SCR): Checklist and Explanation. Annals of Internal Medicine [Internet] 2018; 169, 7, 467-473.

16. Call KT, Lukanen E, Spencer D, Alarcón G, Kemmick Pintor J, Baines Simon A et al. Coverage gains after the affordable care act among the uninsured in Minnesota. Am J Public Health. 2015;105(S5):S658-64. https://doi.org/10.21 05/AJPH.2015.302837.

17. Getrich CM, García JM, Solares A, Kano M. Effective strategies for affordable care act enrollment in immigrant-serving safety net clinics in New Mexico. J Health Care Poor Underserved. 2017:28(2):626-34. https://doi.org/10.1353/ hpu.2017.0063.

18. McGeehan M, DeMaria R, Charney P, Batavia AS. Insurance enrollment at a student-run free clinic after the patient protection and affordable care act. J Community Health. 2017;42(4):785-90. https://doi.org/10.1007/s10900-0170318-7.

19. Orzol S, Hula L. Impact of enroll America on the number of individuals covered through the federally facilitated marketplace. Health Serv Res. 2018; 53(1):341-65. https://doi.org/10.1111/1475-6773.12630.

20. Politi MC, Kuzemchak MD, Liu J, Barker AR, Peters E, Ubel PA, et al. Show me my health plans. MDM Policy Pract. 2016;1-11.

21. Raymond-Flesch M, Lucia L, Jacobs K, Brindis CD. Improving Medicaid access in times of health policy change: solutions from focus groups with frontline enrollment workers. J Health Care Poor Underserved. 2019;30(1): 280-96. https://doi.org/10.1353/hpu.2019.0021.

22. Viramontes O, Hochman M, Serota ML, Delgado E, Moreno G. New enrollment under the affordable care act: leading the way for community health centers in Southern California. BMC Health Serv Res. 2018:18(1):729. https://doi.org/10.1186/s12913-018-3469-z. 
23. Marzilli Ericson KM, Kingsdale J, Layton T, Sacarny A. Nudging leads consumers in Colorado to shop but not switch ACA marketplace plans. Health Aff. 2017;36(2):311-9. https://doi.org/10.1377/hlthaff.2016.0993.

24. Karaca-Mandic P, Wilcock A, Baum L, Barry CL, Franklin Fowler E,

Niederdeppe J, et al. The volume of TV advertisements during the ACA's first enrollment period was associated with increased insurance coverage. Health Affairs. Bethesda, Maryland: Project HOPE/HEALTH AFFAIRS. 2017;36: 747-54.

25. Wright BJ, Garcia-Alexander G, Weller MA, Baicker K. Low-cost behavioral nudges increase Medicaid take-up among eligible residents of Oregon. Health Aff. 2017;36(5):838-45. https://doi.org/10.1377/hlthaff.2016.1325.

26. Housten AJ, Furtado K, Kaphingst KA, Kebodeaux C, McBride T, Cusanno B, et al. Stakeholders' perceptions of ways to support decisions about health insurance marketplace enrollment: a qualitative study. BMC Health Serv Res. 2016;16 [cited 2020 Jul 6] Available from: https://www.ncbi.nlm.nih.gov/ pmc/articles/PMC5100320/.

27. Kreuter MW, McBride TD, Caburnay CA, Poor T, Thompson VLS, Alcaraz Kl, et al. What can health communication science offer for ACA implementation? Five evidence-informed strategies for expanding Medicaid enrollment. Milbank Q. 2014;92(1):40-62. https://doi.org/10.1111/14680009.12040 .

28. Munn Z, Peters MDJ, Stern C, Tufanaru C, McArthur A, Aromataris E. Systematic review or scoping review? Guidance for authors when choosing between a systematic or scoping review approach. BMC Med Res Methodol. 2018;18:143

\section{Publisher's Note}

Springer Nature remains neutral with regard to jurisdictional claims in published maps and institutional affiliations.

Ready to submit your research? Choose BMC and benefit from:

- fast, convenient online submission

- thorough peer review by experienced researchers in your field

- rapid publication on acceptance

- support for research data, including large and complex data types

- gold Open Access which fosters wider collaboration and increased citations

- maximum visibility for your research: over $100 \mathrm{M}$ website views per year

At BMC, research is always in progress.

Learn more biomedcentral.com/submissions 